\title{
The Role of Day Care for Teenage Mothers in a Public School
}

\author{
Kyu-taik Sung \\ The Rackham Graduate School, University of Michigan
}

ABSTRACT: Society stresses that teenage mothers should be helped to finish their high school education. However, their schooling can become a reality only if accompanied by child care.

This paper describes the day care program of an alternative school for teenage mothers and pregnant teenagers. The school provides day care services to the children of the school-age mothers, from "newborn" to "preschooler". The day care center is built into the public school setting.

In addition to day care, a regular high school education is provided as well as health, social and transportation services. Day care helps the mothers continue their education, and these services, in turn, help day care carry out better child care programs. An interdisciplinary approach is taken to run the day care program.

The availability of satisfactory day care plays a crucial role in the young mothers' decision to continue their education. Through the provision of day care, the school increases the number of young mothers entering and remaining in the school. Thus, day care is adopted as the major tool for "engineering" the multi-faceted program into a working system responsive to the needs of the school-age mothers and their children. The role of day care has, therefore, evolved into a new form-one which "engineers" the continuing education program in the public school setting.

\section{Introduction}

One of the major consequences of adolescent pregnancy and childbearing is the increased risk of not completing high school (Stine et al., 1964; Furstenberg, 1979). Educators and concerned citizens stress that the teenage mother should be helped to finish her education and they hope the young mother will become a productive citizen, not solely reliant on government aid for her own and her child's support (Moore, 1978; Scales, 1979; Klerman, 1980).

Return to school of teenage mothers and pregnant adolescents has been a major thrust of existing programs (Goldstein \& Wallace, 1978; Folts, Klerman \& Jekel, 1972). However, for many of the young

The author is grateful to Dorothy Rothrock, the Principal, and Dorothy Larson, Child Care Program Coordinator, CEYW, The Kalamazoo Public School System, for their special cooperation; and to Marion Wijnberg and Ray Lish, Western Michigan University for their encouragement and assistance. Requests for reprints should be addressed to Dr. Kyu-taik Sung, 1812 Longshore Dr., Ann Arbor, Michigan 48105.

Child Care Quarterly, 10(2), Summer 1981

0045-6632/8.11400-0113\$00.95@1981 Human Sciences Press 
mothers, schooling can become a reality only if accompanied by day care (Chaskel, 1969). The availability of satisfactory day care is a crucial factor in the school-age mothers' decision to continue their education (McAnarney \& Adams, 1977; Clapp \& Raab, 1978).

Continuing Education for Young Women (CEYW) of the public school system of Kalamazoo County, Michigan, is an accredited alternative school for pregnant teenagers and teenage mothers (Sung $\&$ Rothrock, 1980). The school is located in a well-equipped high school building in downtown Kalamazoo, a city of 200,000 people.

The Kamamazoo CEYW was the first of such programs established in the state. A major diffference between the Kalamazoo CEYW and the rest of the CEYW programs in the state is that it has a wellorganized child care system built into its program. Using this Kalamazoo CEYW as a model, the Michigan Department of Education has drafted a "state plan" for comprehensive services for young parents and their children. Starting in the Fall of 1979, the concept behind the model will be adapted throughout the state.

This paper describes the current developments in the Kalamazoo CEYW, focusing on the day care program. The report is based on the author's observations and on interviews with members of the program staff, supplemented by data from the school's records and publications.

\section{Goals of the Child Care Program}

The broad goals of the school's child care program are to reduce the potential for child abuse and neglect and to facilitate the normal growth and development of the children of school-age parents through the children's experience in the program (Inter-Agency Committee, 1979).

The objectives set down for the child care program are designed to promote an environment of warmth and security in which the children can thrive. Furthermore, the aim of the program is to assure optimal physical development through activities designed to foster motor development, a sound nutritional program, and the provision of guidance, equipment, and materials in an atmosphere which furnishes maximum cognitive stimulation (Kalamazoo Public Schools, 1979).

\section{Students and Staff}

The students are junior and senior high school-age pregnant students and mothers from other high schools in the county and its neighboring counties.

During the past 13 years, the school has served more than 1,800 young mothers, junior and senior high school-age pregnant students 
and adolescents with young children. A total of 101 girls enrolled in 1979 included the following age-percent distribution: $12(2 \%), 14(4 \%)$, $15(10 \%), 16(26 \%), 17(24 \%), 18(15 \%), 19(7 \%)$, and 20 years or older $(12 \%)$. Fifty-four percent of the students are black; $43 \%$ are white; and the remaining are of other racial backgrounds. Eighty-four percent of the enrollees are single. More than half of all the enrollees already had one or more children at the time of entry and the rest were pregnant. Seventy-eight percent of the students are dropout returns. All were served by the Department of Social Services at enrollment. Over 200 children of adolescent mothers were served during the 1978-1979 school year: 83 percent infants and 17 percent preschoolers. Their ages ranged from six weeks to six years. The educational backgrounds of the students' parents are: eighth grade or less, $24 \%$; some high school, $35 \%$; high school graduate, $33 \%$; some college, $6 \%$; and college graduate, $2 \%$.

The school is staffed by 36 full-time personnel including the principal, elementary and high school teachers, a counselor, nurses, social workers, a day care director, child care workers, child care interventionists, and 14 child care aides (Figure 1). Social workers are assigned to the school under Title XX and are dispatched from Family

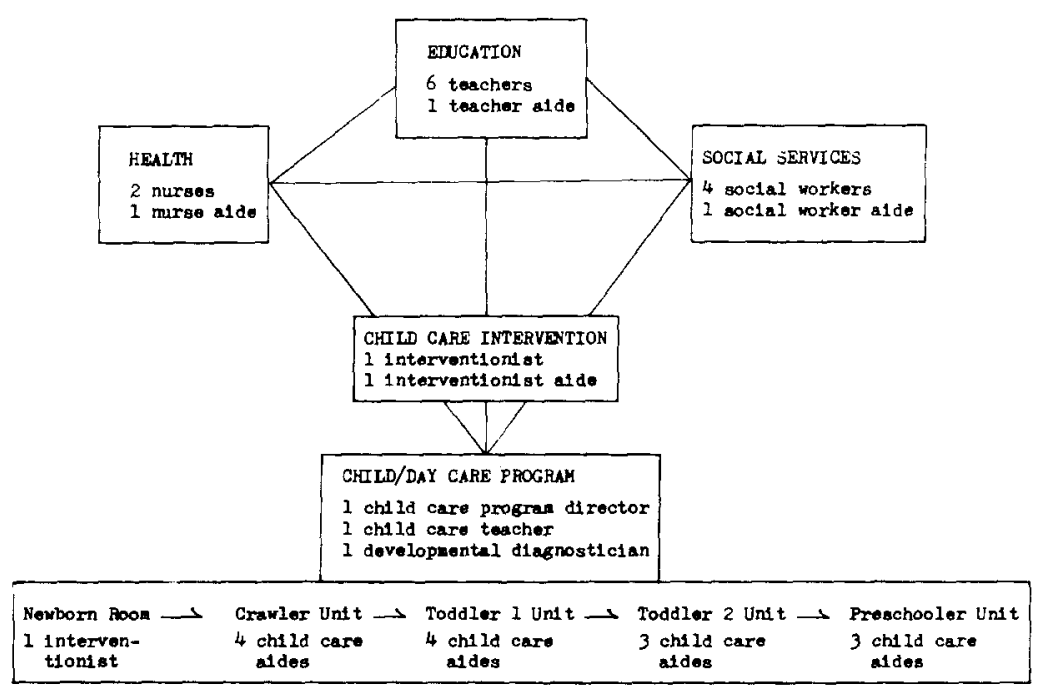

FIGURE 1. Child/Day Care Component in Continuing Education for Pregnant Students and School-Age Mothers. 
and Children's Services. The principal reports to the Office of Superintendent of the public school system.

The school's CEYW consists of four major components; the education unit, the health unit, the social service unit, and the child/day care unit. Each unit has its coordinator who supervises the unit staff and reports to the principal (Figure 1). Transportation and meal services are also provided to the students and their children.

\section{Child Care Program}

The child care program meets the state licensing standards and the Federal day care requirements. The State of Michigan purchases the day care services from the school for the children of low-income families.

Most students express a desire to keep their babies. However, parenting is difficult for the new mothers who are beset by the multiple stresses brought on by poverty, substandard housing, inadequate health information and services, and other problems (Sung, 1978). These are the girls who have few of the resources and supports necessary to cope with these difficulties (Giovannoni \& Billingsley, 1970). The majority of these young women have two or more of the Kadushin's three factors associated with child abuse and neglect (Kadushin, 1967); low-socioeconomic status, a one-parent family structure, and a large number of children. They are not likely to provide optimal environment for their growing children.

The child care program, therefore, shares the basic premise that to help parents learn and change, the stresses in the lives of parents must be alleviated. The child care staff and the social workers assist each other in helping the mothers gain control over their own lives and become better able to fulfill their roles as parents. Parent education in child care is given at home, in class, and in the day care center. It begins from the very basics. The social workers do a fair amount of counseling of fathers who may be performing important child care functions.

\section{Day Care Center}

The school's child care program includes a licensed day care center which meets the health, developmental, and special needs of young children. The center is set up to provide a place for the mothers to leave their children while they are in school. The center also serves to let the mothers work with their children in learning parenting skills (Gross \& Gross, 1977).

The priorities given for admission into the day care program are: (a) children of students of CEYW and other high schools (which 
occupy 50 percent); (b) children of. mothers referred by the Department of Social Services (including family placed in agencies, working mothers, and mothers who are ill); (c) children under the custody of Protective Services of the Department of Social Services (which are mostly abuse and neglect cases); (d) children of parents who are in adult education; (e) children of former CEYW students who are in college; (f) children of a few private citizens (Kalamazoo Public Schools, 1979). The first priority is given to younger mothers.

The day care service is available to the student even after she returns to her original school. Unlike the majority of day care centers in the area, the CEYW's day care center accepts children aged two weeks to six years. The center offers care for the children from 7:30 a.m. to 4:00 p.m., five days a week. Fees are received from a few parents. The fee schedule is set by the Department of Social Services and the school is licensed by the department to accept such fees. The fee of about 10 dollars per day covers care, food, diapers, and individualized instruction.

Many day care centers do not let mothers spend any time with their children in the center. In contrast to this, the school's policy at CEYW requires the mothers to spend a minimum of four hours per week with their children in their center.

The day care program varies to meet the needs of various groups of children. Each group, or unit, offers programmed activities. Art and craft materials are available. Cots, mats, and sheets are also available for the children's naps. Children receive balanced meals prepared by a licensed dietician.

\section{The Five Child Care Units}

The following are the five units and developmental skills that the children should attain in order to progress from one unit to the next (The Kalamazoo Public School System, 1979). The advancement criteria used for the progress cover dimensions of stimulation, socialization, language, self-help, and cognitive and motor development. They are similar to the behavioral criteria specified by Bluma et al. (1976).

1. Newborn Room. This unit serves babies between the ages of 14 days to six months. Here the mother is with her baby all the time. This is a half-day program. The main objective is for the mother to interact with her baby maintaining a positive bond. When the mother returns to school with her infant, she and her child are put in this unit (a homey room) together. The teacher is sent to the room to give the student individualized instruction. The child care worker lends supports necessary to promote developmental parenting skills and works 
between the student and teacher to help the student maintain academic standing. The worker determines when it is appropriate to start separating the mother and child for part of the school day. Here, an interchange of bonding and separation is carefully carried out as a measure of preventive child care.

An expecting mother starts to learn interaction skills even before delivery by observing and experiencing child care in this unit. Thus, the unit functions as a 'laboratory' for pregnant students. The unit is patterned after Raymond Helfer's theory regarding the advantage of early child care intervention designed to prevent child abuse and neglect (Helfer, 1970, 1973). The importance of the unique motherinfant bonding is stressed in the child care program (Gardner, 1978:45; Kegan, et al., 1975).

To progress from "infant" to "crawler", the children should meet the criteria including "responding to attention through smiling," "sitting with support," and "precrawling."

2. Crawler Unit. The children's ages range from seven months to one year. The unit enables the mother to spend a considerable amount of time with her baby. They usually spend a few hours per week in this unit while in school. However, as the baby grows older, there is less contact with the mother in the school. To progress from "crawler" to "toddler", the child should be able to feed self with fingers, use sound to express wants, respond by use of touch, and be aware of self in mirror, among other things.

3. Toddler I Unit. Ages range from one to two years. The children start to have their own ideas, to develop language skills, and often are disruptive. The mother has to learn how to manage her child's activities. To progress from "toddler I" to "toddler II", the children should be able to feed themselves with a spoon, begin to interact with other children, follow simple directions, begin using two word sentences, display positive self-awareness, begin self help activities, etc.

4. Toddler II Unit. The children in this unit are 30 months to three years old. They can now talk, and begin to participate in activities. The main focus is on stimulation and nutrition. Stimulation is achieved through music and gymnastic lessons. Child care activities are a little more structured in this unit. To progress from "toddler II" to "preschooler", the children should use the toilet, dress and undress self, serve self food, use complete sentences, listen to and tell short stories; imitate behavior, language and feelings; make choices and decisions, etc.

5. Preschooler Unit. The children's ages range from four to six years. Many are referred to this unit because young mothers cannot 
take care of them properly. The child care service in this unit centers around social and language development; and learning how to color, write letters, and sing. The mother can spend only one hour a week with her child in this unit. Several children in this group are victims of child abuse and neglect.

Each of the above units has a separate staff and a program to develop the skills of the unit's children. A child care aide takes care of three to four children. The staff members of the day care center meet once a week to plan activities and to discuss the needs of specific children. The members regularly participate in staff development programs inside or outside the school system.

\section{Team Functioning of Service Units}

Various disciplines share their individual training and skills for the maintenance and improvement of the school's child care programs.

The school's routine and curriculum approximate, as much as possible, those of a regular school. Courses in prenatal care and parenting are required for all students. Also provided is remedial and individualized instruction which meet the student's needs. The school does not issue diplomas, but the students can receive diplomas from their home schools.

The health component includes problem prevention, health promotion, and counseling and planning to meet the health needs of the individual mothers and their children. The nurse refers the mother to the OB/GYN clinic and other specialists including pediatricians, conducts maternal health discussions with mothers at the school, makes home visits whenever necessary, and provides family planning counseling and pregnancy tests in an effort to prevent other teenage pregnancies. She also provides a one-week child safety course and a one-week course in child illness. Meeting the nutritional needs of the mother and child receives much emphasis. Under Women, Infants, and Children Program, run by the County Health Department, the mother is provided with protein and iron enriched foods. These foods are provided up to age five for the children. At the same time, the mother and her child are provided with food stamps to supplement their nutritional intake. The school provides the mothers and children with hot lunches five days a week.

The social workers conduct psychological consultations with the mothers and developmental diagnoses to assess the needs of their infants and children. This information assists the mothers and the staff members in solving problems in parent-child relationships. The social workers also help the mother obtain Medicaid.

The social worker and the nurse, as a team, offer counseling on child 
care to the mother. Detecting possible child abuse and neglect is an important task of this team.

Based on information from each of these education, health, and social service units regarding a mother's child abusing and neglecting behavior, the child care interventionists initiate efforts to prevent or alleviate such problems of the mother in close coordination with these units and the child care program.

With mutual understanding and respect, the various disciplines are fused into a single comprehensive sustaining service. They function as a team and share individual training and skills.

\section{Program Effects}

The child care program has facilitated the growth and development of the children, and reduced child neglect and abuse. The program offered each child at his particular time in life the opportunity to continue normal growth and learning. In the 1978-1979 school year, the program helped 200 children progress through various stages of child development. About $80 \%$ of these children moved normally into advanced stages of child care. The rest of them, mostly children with problems including low birth weight and birth defects, were provided with special child care. To prevent and reduce child neglect and abuse, timely and continuous intervention was made in situations encompassing improper supervision, nutritional "battering", neglect due to hazardous living conditions, and need of assistance due to mother's illness or family disorganization. During the past three years, a yearly average of 50 potential neglect cases were detected among the young mothers. However, there were less than three cases reported each year, and no child was institutionalized. An effort of the program to reduce the referral to Protective Services and institutionalization of children has, thus, produced positive results.

Comprehensive child care necessitates intervening with various social, emotional, and health problems that the child's mother brings to the program. The program offered a wide range of experiences to resolve and prevent these problems at a crucial time in the life of a young mother.

Former CEYW students were interviewed in 1978 (Smith, 1979). Fifty were selected at random from a list of students, who participated in CEYW in the 1973-1974, 1974-1975, and 1975-1976 school years. When asked whether they would have attended school if CEYW had not been available, $64 \%$ responded "No". They were also asked to rate the helpfulness of special features of the CEYW program. Child care 
and prenatal classes were rated equally most helpful (90\% agreed). When asked whether they would recommend the CEYW to a sister or friend who was pregnant, $88 \%$ responded "Yes".

CEYW statistics indicate that the program has increased the rate of high school completion among dropouts and decreased incidences of repeat pregnancies among its students, adolescent mothers. During the 1978-1979 school year, 50\% of the students who enrolled in CEYW were returning school dropouts. The CEYW's social workers contacted students in the public school who were known to be pregnant or who were parents, and who dropped out of school. (Those who enroll and then drop out remain on the social worker's list for at least three years or until they reenter school.) Among $80 \%$ of mothers enrolled in CEYW returned after delivery. However, the dropout rate was high: during the 1978-1979 school year, about $50 \%$ of the enrollees dropped out. About $10 \%$ of these dropouts returned to their home schools immediately after leaving CEYW.

In coordination with local clinics, family planning and counseling services were offered to the students as an integral part of the program. In Michigan, family planning education is offered in schools, and clinics can give minors family planning services without parental consent (Sung and Jubb, 1980). In the beginning of the last school year, about $30 \%$ of the mothers used contraceptive methods. At the end of that year, however, use of such methods was reported by $75 \%$ of them. Thus, the potential for repeated pregnancy was substantially reduced.

In general, their academic and employment goals tended to be considerably higher following participation in the CEYW.

\section{Discussion}

The CEYW has demonstrated a new service delivery modality responsive to emerging needs of teenage mothers and their children, mostly from low-income families. In keeping up the multi-faceted program, day care plays the most significant role.

Under the Michigan CEYW, the role of day care has evolved into another innovative form. First of all, the setting in which the day care service is provided is entirely new: it is in the public school. The ages of children being served are expanded, covering infant to preschoolers. The day care staff has become interdisciplinary and much more professional: it includes licensed child care workers, nurses, and social workers; and teachers specialized in child care/parenting. Not only the mothers with children but also the students expecting babies are being 
served: the expecting mothers are taught to prepare for parenting and child care even before delivery.

Day care has, thus, reoriented itself toward a more family-centered and broader service-based system where education, health, and social services are provided as supplementary support and maintenance assistance for the young parents in their child-rearing responsibilities (Peters, 1975; Sung, 1978).

What is more significant is that child care is adopted as the major tool for "engineering" the CEYW program into success. 'The provision of education, health, and social services alone was not enough to help the young mother continue her education: the mother needed child care services also. The lack of child care service can jeopardize the efforts to help the young women continue in school and achieve independence. Thus, we have witnessed important relationships among the CEYW components, particularly the relationship between child care and other services, which must be considered when planning continuing education for school-age mothers.

Studies have shown that the CEYW has encouraged the young mothers to complete high school, enter the job market, and prevent repeated pregnancies; and that those who completed the CEYW program have a better chance of success with their personal lives and with their jobs (Kalamazoo Public Schools, 1979; Smith, 1978; Community Education Center, 1979).

A cost-benefit analysis of the CEYW has not yet been conducted. It may be difficult, as Bane (1976) states, to argue for a free public day care system on the grounds of economic efficiency. However, the longterm effects of the day care service on the future lives of the mothers and their children may turn out to be beneficial in terms of total cost.

At any rate, the innovatively comprehensive and integrated nature of the CEYW, particularly the successful operation of the day care program, and the ever increasing need of society for such a program for school-age mothers, directed the attention of concerned agencies in the state toward a wider adoption of the CEYW model.

With administrative and financial supports to be provided by the state, the Michigan CEYW modality may be reliably replicated in other communities. The extent to which the program is effectively and efficiently adopted and implemented by various other communities should carefully be followed up for the development of the future policy of CEYW.

There is a trend of increase in the number of adolescent mothers who keep their babies. The need of the mothers for day care services will, therefore, increase. The availability of day care will, then, assume a 
position of primary importance to these school-age mothers. As yet, however, little is known about the long-term effect of day care for the school-age mothers and their children. Difficult but important for such a multi-purpose program is to assess levels of family and social functioning of the mothers and their children after leaving the program. Future studies are expected to provide empirical data on these issues.

\section{References}

Bane, M.J. Here to Stay: American Families in the Twentieth Century. New York: Basic Books, 1976, 83-84.

Bluma, S., Shearer, M., Frohman, A., \& Hilliard, J. CHECKLIST: Portage Guide to Early Education. Portage Project, CESA 12, Portage, Wisconsin, 1976.

Community Education Center, 1978-1979 Health Unit Report. The Kalamazoo Public School System, Michigan, 1979. (mimeograph)

Chaskel, R. Illegitimacy-The dimensions of prevention. Social Casework, 1969, 50, 95-101.

Clapp, D.F., \& Raab, R.B. Follow-up of unmarried adolescent mothers. Social Work, 1978, 23, 149-153.

Foltz, A., Klerman, L.V., \& Jekel, F. Pregnancy and special education: Who stays in School? American Journal of Public Health, 1972, 62, 1612-1619.

Furstenberg. Jr., F.F. Unplanned Parenthood: The Social Consequences of Teenage Childbearing. New York: The Free Press, 1979, 81-89.

Gardner, W. Developmental Psychology-An Introduction. Boston: Little, Brown, and Co., 1978, 45-56.

Giovannoni, J.M., \& Billingsley, A. Child neglect among the poor: A study of parental adequacy in family of three ethnic groups. Child Welfare, 1970, 49, 196-204.

Goldstein, H., \& Wallace, M. Services for and the needs of pregnant teenagers in large cities of the United States, 1976. Public Health Reports, 1978, 93, 46-54.

Gross, G., \& Gross, R. Parent-child development center. Children Today, 1977, 6, 19-22.

Helfer, R.E. A plan for protection: The child abuse center. Child Welfare, 1970, 49, 486-493.

Helfer, R.E. The etiology of child abuse. Pediatrics, 1973, 51, 777-779.

Inter-Agency Committee for Services to High Risk Children and Their Families. Background Paper: Comprehensive programs for pregnant adolescents, school-age parents and their families. Michigan Department of Education, 1979.

Kadushin, A. Child Welfare Services. New York: Mcmillan, 1967, 222-228.

Kalamazoo Public Schools, Continuing Education for Young Women and Title XX, June 13, 1979.

The Kalamazoo Public School System, Early Childhood Developmental Goals, Kalamazoo Public Schools' Comprehensive and Integrated Services for Young Parents and their Children, 1979.

Kegan, J., Kearsley, R.B., \& Zelano, P.R. The Effects of Infant Day Care on Psychological Development. Paper presented at a symposium on "The Effect of Early Experience on Child Development." American Association for Advancement of Science, Boston, February 1976.

Klerman, L.V. Adolescent pregnancy: A new look at a continuing problem. American Journal of Public Health, 1980, 70, 776-778.

McAnarney, E.R., \& Adams, B.N. Development of an adolescent maternity project in Rochester, New York. Public Health Reports, 1977, 92, 154-159. 
Moore, K.A. Teenage childbirth and welfare dependency. Family Planning Perspectives, 1978, 10, 233-235.

Peters, L.C. Day care: The problems, the process, the prospects. Child Care Quarterly, $1975,4,172-179$.

Scales, P. The context of sex education and the reduction of teen-age pregnancy. Child Welfare, 1979, 58, 263-273.

Smith, C. Report to Continuing Education for Young Women Advisory Council, Kalamazoo Public Schools, Michigan, June 13, 1978. (mimeograph)

Stine, O.C., Rider, R.V., \& Sweeney, E. School leaving due to pregnancy in an urban adolescent population. American Journal of Public Heaith, 1964, 54, 1-6.

Sung, K. The integrated day care program: An example in Korea. Child Care Quarterly, $1978,7,131-141$.

Sung, K. Family planning services for indigent women and girls. Health and Social Work, 1978, 3, 152-172.

Sung, K., \& Jubb, W.H. Family Planning Education for Adolescents. Secondary Education Today, 1980, 21, 9-18.

Sung, K., \& Rothrock, D. An alternative school for pregnant teenagers and schoolage mothers. Child Welfare, 1980, 59, 427-436. 